\title{
Treatment of adult asthma: is the diagnosis relevant?
}

\author{
PETER LITTLEJOHNS, SHAH EBRAHIM, ROSS ANDERSON
}

From the Department of Clinical Epidemiology and Social Medicine, St Georges Hospital Medical School, London

ABSTRACT The diagnosis and management of chronic respiratory symptoms was studied in all adults aged 40-70 years in a group general practice. A respiratory symptoms screening questionnaire was sent to 2387 men and women, of whom 1444 (85\% of those who had not moved or died) responded. The 509 subjects reporting symptoms were sent a detailed questionnaire and invited to have their respiratory function tested. Of these, $324(64 \%)$ responded, of whom $256(79 \%)$ had spirometry. A diagnosis of chronic bronchitis was reported by $3.9 \%$ of the men and $2 \cdot 1 \%$ of the women, and a diagnosis of asthma by $4.7 \%$ of the men and $3.3 \%$ of the women. Wheezing in the preceding year was reported by $18 \%$ of the men and $15 \%$ of the women, and $16.7 \%$ of the men and $7 \cdot 1 \%$ of the women satisfied the Medical Research Council criteria for chronic bronchitis. Bronchodilator treatment was being taken by $12 \%$ of the patients with symptoms, regular cough linctus by $10 \%$, and regular antibiotics by $5 \%$. After the frequency and severity of respiratory symptoms had been controlled for wheezing patients reporting a diagnosis of asthma were prescribed bronchodilatory drugs three times more often than those labelled as having chronic bronchitis and 12 times more often than those without a diagnostic label. Eleven per cent of general practitioner consultations resulted in a referral to hospital. Referral was unrelated to the diagnosis given, but depended on the degree of respiratory disability and handicap experienced by the patient. Our findings confirm the relevance of the diagnostic label to the drug management of chronic wheezing disorders, but further investigation of the diagnostic process is needed to establish why some patients with severe wheeze remain untreated.

\section{Introduction}

An increase in asthma morbidity ${ }^{2}$ and possibly mortality $^{34}$ has meant that its management by general practitioners has come under scrutiny. Criticisms have included underdiagnosis, ${ }^{5}$ undertreatment, ${ }^{6}$ and delayed referral to hospital. ${ }^{7}$ Reasons put forward to explain this apparent deficiency of care have included lack of agreement between general practitioners on the management of acute asthma, ${ }^{8}$ patients' poor compliance,' and the changing nature and treatment of the disease itself. $^{10}$ In adults there is the additional problem of differentiating asthma from other disorders leading to airflow limitation. " Advice on the treatment of these adult wheezers has ranged from ignoring the subtleties of differential diagnosis and treating symptoms empirically ${ }^{12}$ to the importance of making a definite diagnosis of asthma. ${ }^{13}$

\footnotetext{
Address for reprint requests: Dr P Littlejohns, Department of Clinical Epidemiology and Social Medicine, St Georges Hospital Medical School, London SW17 ORE.
}

To assess the effects of a diagnostic label on the management of patients suffering with chronic respiratory symptoms, we explored the relation between aspects of their management (drug treatment, general practitioner and hospital attendances) and sociodemographic factors, the type and severity of symptoms, and diagnosis. We studied all patients aged 40-70 years in an urban group practice. The prevalence, diagnosis, and associated morbidity of chronic respiratory symptoms is the subject of another paper. ${ }^{14}$

\section{Methods}

The age-sex register of a group general practice in South West London (three principals and one trainee) was used to identify all men and women aged 40-70 years. They were sent a previously validated screening questionnaire, which inquired about winter morning cough, winter morning phlegm, occasional wheeze, shortness of breath while washing and dressing, and distance walked on the level before they became short of breath. ${ }^{15} \mathrm{Up}$ to two reminders were sent. Those who 
responded positively to at least one question were sent a detailed respiratory questionnaire, which included questions on chronic bronchitis from the Medical Research Council's (MRC) respiratory questionnaire. ${ }^{16}$ Questions were also asked about the frequency and duration of symptoms; walking capability on the level, on hills, and on stairs (disability); and the effect of the respiratory illness on everyday life and activities (handicap). Subjects were asked to record what they considered to be the diagnosis of their condition. The diagnosis recorded in the general practitioner's case notes was also obtained. Subjects were asked about the treatment they had received in the preceding year and contact with health services (general practitioner and hospital as inpatient and outpatient). All subjects completing the detailed questionnaire were invited to the surgery for respiratory function tests. The forced expiratory volume in one second $\left(F E V_{1}\right)$, forced vital capacity (FVC), and peak expiratory flow (PEF) were measured with a McDermott spirometer, which was calibrated daily. The best of five measurements was recorded. Height was measured to the nearest centimeter. The response to a bronchodilator challenge was measured 10 minutes after inhalation of $1 \mathrm{mg}$ of terbutaline (four puffs) from a Nebuhaler (Astra). Predicted values for lung function were calculated on the basis of the regression equations of Cotes. ${ }^{17}$ Prevalence rates were calculated, the denominator being the number of responses to the screening questionnaire after adjustment for the response to the detailed questionnaire. Ninety five per cent confidence limits for prevalence were calculated on the basis of the actual number of respondents. Subjects were assigned to social class groups according to the Registrar General's classification ${ }^{18}$; married women were classified according to their husband's occupation and the main lifetime occupation was used for retired people.

The effects of various factors on drug prescription and service utilisation were initially analysed by the $\chi^{2}$ test. Significant associations were further expressed as odds ratios with their $95 \%$ confidence limits. When two independent variables were interrelated the independent effects were examined by the technique of two factor logistic regression. All analyses were carried out by means of the Statistical Package of Social Science (SSPS-X) on the University of London's Amdahl computer.

The reliability of the detailed questionnaire and the screening questionnaire was assessed in a subgroup of subjects who were invited to complete the questionnaires a second time three weeks later. The repeatability of questions was assessed by the kappa statistic. Further validation of the screening questionnaire was undertaken by inviting a random sample of subjects who responded negatively to all screening questionnaires to complete a detailed questionnaire and have their respiratory function assessed.

\section{Results}

RESPONSE RATES

The screening questionnaire was sent to all $238 \overline{\bar{p}}$ eligible patients on the age-sex register. Six hundre and ninety were returned uncompleted because the person had moved away or died. The effective sample was therefore 1697 (758 men, 939 women).

The number of adequately completed question $\overrightarrow{\vec{\omega}}$ naires was 1444, giving an effective response rate oळ $85 \%$. Five hundred and nine people respondect positively to at least one of the screening questions (figure) and were therefore sent a detailed question naire. Questionnaires were completed by $324(64 \%)$ oP these patients, $256(79 \%)$ of whom were seen at theo surgery and had spirometry performed. There was no difference in response rates between men and women? The mean age of positive responders to the screening questionnaire was 58.8 (SD 9.1) years for men and 57.6 (SD 9.1) years for women; $56 \%$ were male. Negative responders were slightly younger (men 54.0 , womer 55.5 years) and $39 \%$ were male. Those completingo detailed questionnaires and spirometry had the same sex, age, and symptom distribution as the initiat positive responders.

\section{PREVALENCE RATES}

The prevalence of a self reported diagnosis of chroniक्ष

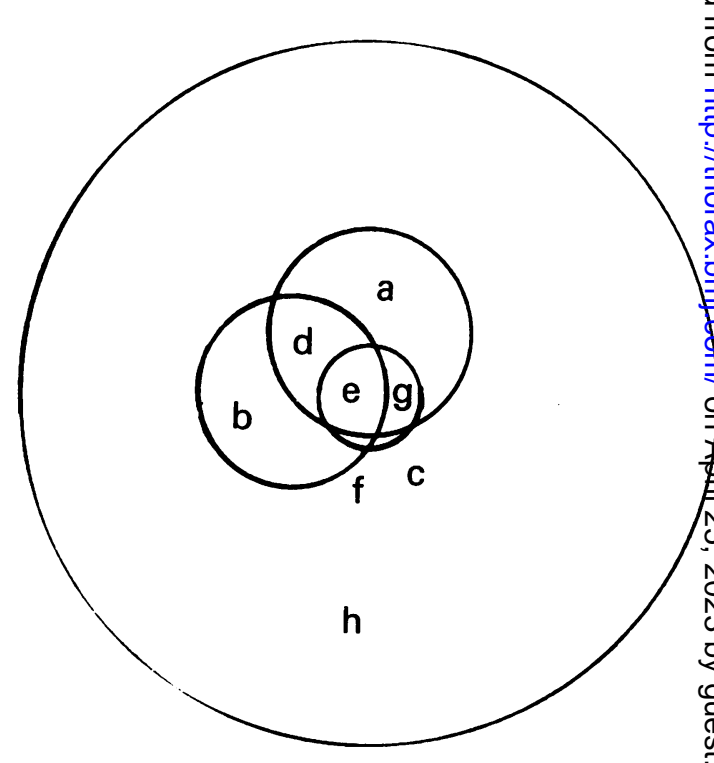

Respiratory symptoms in a population of 1444 aged 40-70 years. $a$-wheeze: $9 \cdot 1 \% ; b$-cough and phlegm: $6.7 \%$, $c$-shortness of breath: $1.3 \% ; d-c o u g h$ and phlegm and wheeze: $8.7 \% ; e-c o u g h$ and phlegm and wheeze and shortness of breath: $5.5 \% ; f$-cough and phlegm and shortness of breath: $0.8 \% ; \mathrm{g}$-wheeze and shortness of breath: $2.5 \%$; $h$-no symptoms: $65 \cdot 4 \%$. 
bronchitis was $3.9 \%$ ( $95 \%$ confidence limits (CL) $1 \cdot 6$, $6 \cdot 1 \%$ ) in men and $2 \cdot 1 \%(C L 0 \cdot 2,4.0 \%)$ in women. The prevalence of chronic bronchitis as defined by the MRC questionnaire was $16.7 \%$ (CL 8.7, 16.5\%) in men and $7 \cdot 1 \%(\mathrm{CL} \cdot 3 \cdot 7,10.5 \%)$ in women. The prevalence of a self reported diagnosis of asthma was $4 \cdot 7 \%$ (CL 2.2, $7 \cdot 2 \%$ ) in men and $3 \cdot 3 \%$ (CL 1.0, $5 \cdot 6 \%$ ) in women. The prevalence of any reported wheeze in the preceding year was $18.0 \%$ (CL 13.5, $22.5 \%$ ) in men and $15.0 \%$ (CL 10.3 19.7\%) in women, and of wheeze at least once a week in the last year $9.4 \%$ (CL 6.0, $12.8 \%$ ) in men and $2.5 \%$ (CL $0.5,4.5 \%$ ) in women. The prevalence of any reported wheeze plus associated respiratory disability was $5.9 \%$ (CL $3 \cdot 2,8 \cdot 6 \%$ ) in men and $5 \cdot 6 \%(C L 2 \cdot 6,8 \cdot 6 \%)$ in women. The prevalence of wheeze at least once a week and associated respiratory disability was $5.4 \%$ (CL 2.8, 8.0\%) in men and $1.5 \%$ (CL $0,3 \cdot 1 \%)$ in women. The prevalence of airway reversibility of more than $20 \%$ after terbutaline challenge was $4 \cdot 1 \%$ in men and $3 \cdot 2 \%$ in women. Only $35 \%$ of patients with a $20 \%$ response reported a label of asthma.

\section{DRUG TREATMENT}

Table 1 shows the treatment prescribed over the preceding year for patients labelled as having asthma or chronic bronchitis, those with chronic bronchitis as defined by the MRC questionnaire (without a label of chronic bronchitis), and those wheezing at least once a week without a label of asthma.

Thirty nine $(12 \%)$ of the responders who had respiratory symptoms were having some type of "antiasthmatic" medication (bronchodilators, inhaled or oral corticosteroids, aminophylline, or sodium cromoglycate). Thirty three $(10 \cdot 2 \%)$ were taking cough linctus regularly and $15(4 \cdot 6 \%)$ were taking regular antibiotics.

The most common medication prescribed for patients with a diagnosis of asthma was a bronchodilator inhaler; for chronic wheezers without a diagnostic label the most common medication was cough linctus. This means (allowance being made for response rate) that $4 \cdot 2 \%$ of the population aged $40-70$ years had been prescribed bronchodilator treatment. Prescription of bronchodilator drugs was more common in subjects who reported frequent symptoms of wheeze and shortness of breath, respiratory disability and handicap, and who had been referred to hospital (table 2). They were more likely to report that they had been given a diagnostic label of asthma, and a label of asthma rather than chronic bronchitis. After frequency of wheezing had been controlled for by two factor logistic regression modelling, patients with a label of asthma were still prescribed bronchodilator drugs $4 \cdot 1$ (confidence limits $1 \cdot 25,13.62)$ and $15.7(\mathrm{CL}$ $6.98,35.4)$ times as often as patients with a label of chronic bronchitis and unlabelled patients respectively. When all associated severity variables (frequency of wheeze, shortness of breath, respiratory disability, and handicap) were controlled for in a single logistic regression model, patients reporting a label of asthma remained 3.08 (CL 1.05, 8.95) and 12.2 (CL 5.30, 28.21) times more likely to have been prescribed bronchodilator drugs than patients reporting a label of chronic bronchitis and unlabelled patients.

When shortness of breath and wheezing were placed in a two factor logistic model, frequency of shortness of breath was the most important predictor of drug prescription (odds ratio $2.3(\mathrm{CL} \mathrm{1.04,4.95))}$ and the

Table 1 Drug treatment of patients with a label of asthma and chronic bronchitis* and people with chronic wheeze (at least once a week) and chronic bronchitis $\dagger$ without a diagnostic label

\begin{tabular}{|c|c|c|c|c|}
\hline & \multicolumn{4}{|c|}{$\%$ of patients with } \\
\hline & $\begin{array}{l}\text { asthma* } \\
(n=37 \ddagger)\end{array}$ & $\begin{array}{l}\text { chronic bronchitis* } \\
(n=27 \ddagger)\end{array}$ & $\begin{array}{l}\text { unlabelled chronic } \\
\text { wheeze } \\
(n=32)\end{array}$ & $\begin{array}{l}\text { unlabelled chronic } \\
\text { bronchitis } \dagger \\
(n=79)\end{array}$ \\
\hline Bronchodilator inhaler & 73 & 15 & 13 & 4 \\
\hline Bronchodilator tablets & 3 & 4 & 0 & 0 \\
\hline Steroid tablets & 5 & 4 & 0 & 0 \\
\hline Steroid inhalers & 49 & 15 & 6 & 1 \\
\hline Sodium cromoglycate & 8 & 0 & 0 & 0 \\
\hline Aminophylline & 24 & 8 & 0 & 0 \\
\hline Antibiotics & 0 & 8 & 9 & 6 \\
\hline Linctus & 3 & 15 & 22 & 6 \\
\hline Oxygen & 0 & 8 & 0 & 0 \\
\hline \multicolumn{5}{|l|}{ Influenza vaccination } \\
\hline never & 67 & 69 & 72 & 72 \\
\hline once & 12 & 13 & 16 & 18 \\
\hline on a few occasions & 9 & 9 & 6 & 9 \\
\hline every winter & 12 & 9 & 6 & 1 \\
\hline
\end{tabular}

* As reported by the patient.

$\dagger$ As defined by the Medical Research Council questionnaire.

$\ddagger$ Four patients had a diagnosis of both asthma and chronic bronchitis and are represented in both columns. 
Table 2 Unadjusted odds ratios (with 95\% confidence limits) for the prescription of bronchodilator drug treatment, consultation with a general practitioner, referral to an outpatient clinic, and admission to hospital according to frequency of symptoms, associated disability and handicap, reported diagnosis, and use of services for 324 patients with respiratory symptoms

\begin{tabular}{|c|c|c|c|c|}
\hline Symptoms & Drug treatment & $\begin{array}{l}\text { General practitioner } \\
\text { consultation }\end{array}$ & Outpatient referral & Inpatient episode \\
\hline $\begin{array}{l}\text { Shortness of breath (at least once a week } \\
v \text { less than once a week) }\end{array}$ & $3.05^{*}(1 \cdot 54,6.04)$ & $2 \cdot 23^{*}(1 \cdot 35,3 \cdot 69)$ & $0 \cdot 78(0 \cdot 50,2 \cdot 31)$ & $3 \cdot 05^{*}(1 \cdot 00,9 \cdot 35)$ \\
\hline $\begin{array}{l}\text { Wheeze (at least once a week } \\
v \text { less than once a week) }\end{array}$ & $2 \cdot 71^{*}(1 \cdot 27,5 \cdot 83)$ & $2 \cdot 54^{*}(1 \cdot 37,4 \cdot 75)$ & $1.22(0.50,3 \cdot 06)$ & $1.04(0.67,4.95)$ \\
\hline $\begin{array}{l}\text { Diagnostic label } \\
\text { Label of asthma } \\
\text { Asthma } v \text { chronic bronchitis label }\end{array}$ & $\begin{array}{r}16 \cdot 70^{*}(7 \cdot 38.36 \cdot 60) \\
3 \cdot 84^{*}(1 \cdot 17,12 \cdot 23)\end{array}$ & $\begin{array}{l}3 \cdot 52 *(1 \cdot 64,7 \cdot 38) \\
1 \cdot 42(0 \cdot 45,4 \cdot 48)\end{array}$ & $\begin{array}{l}1.93(0.85,4 \cdot 57) \\
0 \cdot 73(0.22,2 \cdot 44)\end{array}$ & $\begin{array}{l}2.41(0 \cdot 64,9 \cdot 00) \\
1.08(0 \cdot 17,6 \cdot 82)\end{array}$ \\
\hline $\begin{array}{l}\text { Disability } \\
\text { Difficulty walking on the level }\end{array}$ & $2 \cdot 77^{*}(1 \cdot 19,6 \cdot 45)$ & $1.67(0.83,3.38)$ & $3 \cdot 38 *(1 \cdot 52,7 \cdot 53)$ & $3.94^{*}(1 \cdot 14,13 \cdot 57)$ \\
\hline $\begin{array}{l}\text { Handicap } \\
\text { Interference with normal activities }\end{array}$ & $3 \cdot 21^{*}(1 \cdot 60,6 \cdot 44)$ & $6 \cdot 22 *(3 \cdot 65,10 \cdot 58)$ & $4 \cdot 17^{*}(2 \cdot 12,8 \cdot 1)$ & $7 \cdot 38^{*}(1 \cdot 97,27 \cdot 43)$ \\
\hline $\begin{array}{l}\text { Use of services } \\
\text { Consultation with general practitioner more } \\
\text { than once } v \text { once or less }\end{array}$ & $1.97(0.85,4 \cdot 70)$ & - & $2 \cdot 84^{*}(1 \cdot 25,6 \cdot 42)$ & $4 \cdot 3(0 \cdot 96,20 \cdot 9)$ \\
\hline $\begin{array}{l}\text { Outpatient attendance in preceding year } \\
\text { Inpatient episode in preceding year }\end{array}$ & $\begin{array}{l}2 \cdot 57^{*}(1 \cdot 14,5 \cdot 75) \\
7 \cdot 15^{*}(2 \cdot 26,22 \cdot 55)\end{array}$ & $\overline{-}$ & $\overline{-}$ & $\frac{47 \cdot 7 *(10 \cdot 01,221 \cdot 40)}{-}$ \\
\hline
\end{tabular}

association with frequency of wheezing lost statistical significance (odds ratio $1 \cdot 8$ (CL $0 \cdot 78,4 \cdot 1)$ ).

Treatment with bronchodilator drugs was not associated with age, sex, social class, frequency of the symptoms of cough and phlegm, or frequency of consultation with a general practitioner.

\section{USE OF SER VICES BY PATIENTS WITH}

RESPIRATORY SYMPTOMS

Table 3 shows the consultation pattern for patients labelled as having asthma and chronic bronchitis, unlabelled wheezers, and patients who fulfilled the Medical Research Council definition of chronic bron- chitis but who had not received a diagnostic labelio Patients with a diagnostic label were more frequento attenders at the general practitioner's surgery and more likely to have been referred to a hospita? outpatient department or admitted to hospital.

\section{Consultation with a general practitioner}

Consulting rates for subjects reporting symptoms in the preceding year was $160 / 1000$ people aged $4 0 - 7 \longdiv { Q }$ years (mean 2.6 consultations a patient). Consulting rates for asthmatic patients were $19 \cdot 5 / 1000$ (mean 2. consultations) and for patients with chronic bronchitis $12 \cdot 9 / 1000$ (mean $4 \cdot 1$ consultations).

Table 3 Use of services by patients labelled as having asthma and chronic bronchitis and people with chronic wheeze (at least once a week) and chronic bronchitis* without a diagnostic label

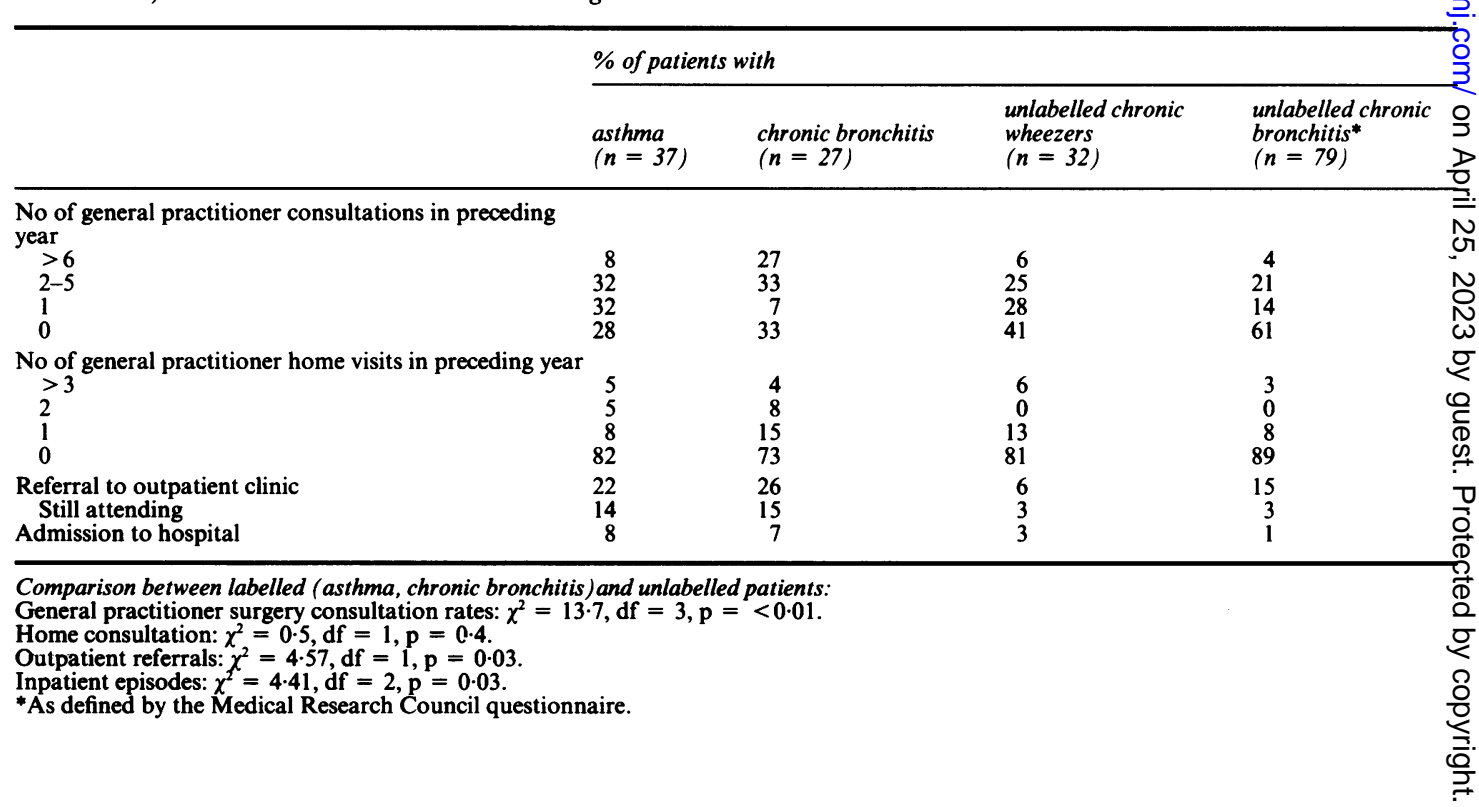


Patients consulting their general practitioner in the preceding year were more likely to report frequent wheeze and shortness of breath (table 2) but not frequent cough and phlegm. When shortness of breath and wheeze were placed in a two factor logistic regression model the association between general practitioner attendance and frequency of wheeze lost statistical significance (odds ratio $1 \cdot 89$ (CL 0.96, 3.72)) but shortness of breath remained an independent predictor of general practitioner attendance (odds ratio 1.81 (CL 1.05, 3.15)).

Patients consulting their general practitioner were more likely to report disability (difficulty in walking on the level) and handicap (restriction of normal activities) and to have acquired a label of asthma. The best predictor of a general practitioner consultation in the preceding year was the degree of handicap experienced by the patient.

Attendance at the general practitioner's surgery in the preceding year by those with symptoms was not associated with age, sex, or social class. They were not more likely to have acquired a label of asthma than of chronic bronchitis.

\section{Referral to an outpatient clinic}

Eleven per cent of consultations for respiratory symptoms resulted in a referral to an outpatient clinic. Referred patients reported more respiratory disability and handicap and consulted their general practitioner frequently. Frequency of visiting the general practitioner remained a significant predictor of referral after the degree of disability had been controlled for (odds ratio 2.64 (CL 1.15, 6.07)). Respiratory handicap had the greatest effect on the decision to refer.

Referral to a respiratory outpatient clinic was not related to age, sex, social class, frequency of symptoms of wheeze, shortness of breath, cough, or phlegm. Patients with a label of asthma were not referred more frequently than those with a label of chronic bronchitis.

\section{Inpatient episodes}

Only 13 patients had been admitted to hospital in the preceding year. Admission was related to the frequency of reported shortness of breath, disability, handicap, and outpatient attendance. Admission was not related to age, sex, social class, frequency of wheeze, having a diagnostic label, or frequency of consultation with a general practitioner in the preceding year.

Of the 13 patients admitted in the preceding year, 12 $(92 \%)$ had consulted their general practitioner in the year and $10(77 \%)$ had seen their general practitioner on more than two occasions that year; but these 10 represented only $13 \%$ of the 80 patients who had consulted their general practitioner on more than two occasions that year.

\section{Discussion}

Using a single group practice means that the diagnostic labels and disease management reflect the views of a limited number of general practitioners. A London practice, however, has considerable migration of patients, so that the labels and treatment had been given by more doctors than were in the practice. We obtained the data retrospectively, thus avoiding the possible diagnostic bias in many prospective general practice based studies using volunteer general practitioners. We achieved a high response to the initial screening questionnaire, which allowed estimates of the degree of bias in response to the detailed questionnaire and lung function tests to be made. Symptoms at screening did not differ between those who did and did not attend for detailed assessment, and their ages were similar. Any major response bias with respect to the respiratory state of the patients is therefore unlikely. Thus the symptom and disease prevalence rates are likely to be representative of those of the general population. Possibly, however, the responders were different in terms of potentially important aspects of diagnosis or treatment, such as satisfaction with treatment. The most likely direction of the bias is a higher response from "labelled" patients on treatment, which would tend to overestimate levels of diagnosis and treatment in the community.

It has been recommended that patients with wheeze should be assessed to see whether they respond to treatment with bronchodilators or other treatment (sodium cromoglycate or corticosteroids). ${ }^{19}$ In the present study prescription of these drugs was associated with reported wheezing, shortness of breath, associated disability and handicap, and the acquisition of a diagnostic label. The latter association remained significant after disease severity had been controlled for. Patients with a label of asthma were 12 times as likely to be prescribed medication as those without a label but had similar frequencies of wheezing, shortness of breath, respiratory disability, and handicap. Only $13 \%$ of patients who wheezed at least once a week and who did not report having a label of asthma had been prescribed bronchodilator drugs. These findings parallel those of studies on wheezing children, in which the prescription of bronchodilator drug treatment was more likely in those patients with a label of asthma. ${ }^{56}$ Two basic hypotheses could explain the association between a diagnostic label and treatment. Either the doctor makes a diagnosis, on the basis of which treatment is prescribed (for example, a patient presents with wheeze, a diagnosis of asthma is made, and bronchodilator treatment is prescribed) or the doctor prescribes on the basis of symptoms and the label is given if the treatment, such as a therapeutic trial of bronchodilator drugs, is effective. Whereas the first approach is more often taught at medical school, 
the second, empirical, approach is perhaps used more often in practice and has been strongly advocated in recent years. ${ }^{12}$ This approach should lead to the identification of previously unrecognised and hence unlabelled asthma. In this study the finding that about a quarter of the patients who reported wheeze severe enough to cause disability and handicap had not been prescribed drug treatment in the preceding year suggests that either the doctors or the patients believed that treatment was not relevant to them. Perhaps these patients were considered to be suffering from irreversible airways disease and were considered unlikely to benefit (possibly a trial of bronchodilator treatment or corticosteroids had been undertaken but not recorded in the notes or recollected by the patient) or their symptoms were considered too mild to warrant medication. The finding that shortness of breath rather than wheeze was the main predictor of bronchodilator drug treatment suggests that general practitioners may wish to treat wheeze only when accompanied by shortness of breath. There was also a suggestion that patients consider shortness of breath rather than wheeze as the main criterion for seeking medical assistance.

This community survey supports the evidence from hospital studies that showed the importance of the diagnostic label in the treatment of chronic respiratory symptoms. ${ }^{13}$ In view of the difficulty of distinguishing asthma from chronic bronchitis in adults, ${ }^{14}$ further research into patients' and doctors' perceptions of specific respiratory symptoms and their influence on drug prescribing and compliance is needed. This should be a priority because prescriptions of bronchodilator drugs are continuing to increase without a fall in asthma morbidity and mortality, and potentially detrimental effects are being identified. ${ }^{2021}$

We thank Drs G J Pollock, P Forrester, and V Terrell for access to their patients and the secretarial staff of the surgery for organising the visits to patients. The terbutaline and nebuhalers were provided by Astra Pharmaceuticals. SE was supported by the Wellcome Trust.

\section{References}

1 Anderson HR. Increase in hospitalisation for childhood asthma. Arch Dis Child 1978;53:295-300.

2 Office of Population Censuses and Surveys, Royal
College of General Practitioners, and Department o⿸ Health and Social Security. Morbidity statistics from general practice. Third national study 1981-82. London HMSO, 1986.

3 Burney PGJ. Asthma mortality in England and Wales evidence for a further increase, 1974-84. Lance? 1986;ii:323-6.

4 Markowe HLJ. Asthma mortality in England and Wales $\overrightarrow{0}$ Lancet 1986;ii:636.

5 Speight ANP, Lee DA, Hey EN. Underdiagnosis and treatment of asthma in childhood. Br Med J 1983? 286:1253-8.

6 Anderson HR, Bailey PA, Cooper JS, Palmer JCA Influence of morbidity, illness label, social factors and health service factors on drug treatment of childhoo asthma. Lancet 1981;ii:1030-2.

7 British Thoracic Society. Death from asthma in two regions of England. Br Med J 1982;285:1251-5.

8 Anderson HR, Freeling P, Patel SP. Decision-making i acute asthma. J R Coll Gen Pract 1983;33:105-8.

9 Harding JM, Modell M. How patients manage asthma. $R$ Coll Gen Pract 1985;35:226-8.

10 Seaton A. Asthma-contrasts in care. Thorax 1978 33:1-2.

11 Wardman AG, Binns V, Clayden AD, Cooke NJ. The्छ diagnosis and treatment of adults with obstructive airways disease in general practice. $\mathrm{Br} J$ Dis Ches 1986;80:19-26.

12 Gross NJ. COPD: a disease of reversible air-flow obstruc tion. Am Rev Respir Dis 1986;133:725-6.

13 Bucknall CE, Robertson C, Moran F, Stevenson RD员 Differences in hospital asthma management. Lance 1988;I:748-50.

14 Littlejohns P, Ebrahim S, Anderson HR. Prevalence and diagnosis of chronic respiratory symptoms in adults. $B$ Med J 1989;298: 1556-60.

15 Williams BT, Nicholl JP. Prevalence of hypoxaemie chronic obstructive lung disease with reference to long term oxygen therapy. Lancet 1985;ii:369-72.

16 Medical Research Council. Definition and classifications of chronic bronchitis for clinical and epidemiologica $\mathrm{B}$. purposes. Lancet 1965;i:775-9.

17 Cotes JE. Lung function: assessment and application in medicine. 3rd ed. Oxford: Blackwell, 1975.

18 Office of Populations, Censuses and Surveys. Classifica은

tion of occupations. London: HMSO, 1984.
19 Mitchell DM, Gildeh P, Rehain M, Dimond AH, Collins? JV. Effects of predisolone in chronic airflow limitation Lancet 1984;ii:193-5.

20 Vathenen AS, AJ Knox, Higgins BG, Britton JRN Tattersfield AE. Rebound increase in bronchial ref sponsiveness after treatment with inhaled terbutaline
Lancet 1988; i:554-7.

21 Crane J, Pearce N, Flatt A, et al. Prescribed fenoterol an $\varnothing$ death from asthma in New Zealand, 1981-83: case $\$$ control study. Lancet 1989;i:917-22. 